\title{
The use of reproductive healthcare at commune health stations in a changing health system in Vietnam
}

\author{
Anh D Ngo ${ }^{1 *}$ and Peter S Hill ${ }^{2}$
}

\begin{abstract}
Background: With health sector reform in Vietnam moving towards greater pluralism, commune health stations (CHSs) have been subject to growing competition from private health services and increasing numbers of patients bypassing CHSs for higher-level health facilities. This study describes the pattern of reproductive health (RH) and family planning (FP) service utilization among women at CHSs and other health facilities, and explores sociodemographic determinants of RH service utilization at the CHS level.

Methods: This study was based on a cross-sectional survey conducted in Thua Thien Hue and Vinh Long provinces, using a multi-stage cluster sampling technique. Questionnaire-based interviews with 978 ever-married women at reproductive age provided data on socio-demographic characteristics, current use of FP methods, history of RH service use, and the health facility attended for their most recent services. Multiple logistic regression analyses were used to identify socio-demographic determinants of their use of CHS RH services.

Results: Eighty nine percent of ever-married women reported current use of birth control with $49 \%$ choosing intra-uterine device (IUD). Eighty nine percent of pregnant women attended facility-based antenatal care (ANC) with $62 \%$ having at least 3 check-ups during their latest pregnancy. Ninety one percent of mothers had their last delivery in a health facility. Seventy-one percent of respondents used CHS for IUD insertion, 55\% for antenatal check-ups, and 77\% gynecological examination. District and provincial/central hospitals dominated the provision of delivery service, used by $57 \%$ of mothers for their latest delivery. The percentage of women opting for private ANC services was reported at 35\%, though the use of private delivery services was low (11\%). Women who were farmers, earning a lower income, having more than 2 children, and living in a rural area were more likely than others to use ANC, delivery, and/or gynecological check-up services at the CHS.

Conclusions: Women choice of providers for FP and RH services that help them plan and protect their pregnancies is driven by socio-economic factors. While the CHS retains significant utilization rates, it is under challenge by preferences for hospital-based delivery and the growing use of private ANC services.
\end{abstract}

\section{Background}

With the introduction of its "Doi Moi" or 'renovation' policy in 1986, Vietnam has shifted from a centrally planned towards a market-oriented economy. Health sector reform has introduced user fees in public

\footnotetext{
* Correspondence: Anh.Ngo@unisa.edu.au

'Social Epidemiology and Evaluation Research Group, School of Health Sciences, University of South Australia, City East Campus, Adelaide, SA 5000, Australia. (Formerly, Vietnam Evidence for Health Policy Project, School of Population Health, University of Queensland. Health Strategy and Policy Institute, 138 Giang Vo Str., Hanoi, Vietnam

Full list of author information is available at the end of the article
}

hospitals and legalized private practice. In urban centers in particular, the private health sector has been growing rapidly, and increasingly is in competition with the public sector in providing health services. These changes have produced profound effects on the use of health services at state health facilities, including $\mathrm{RH}$ care at the local CHS - the basic unit of the primary healthcare system in Vietnam [1,2].

To date, no study has examined the use of FP and primary RH services in the context of the current healthcare system in Vietnam, as it shifts from a state monopoly to a more pluralist system. To address this

\section{Biomed Central}


shortcoming, this study aims to describe the pattern of $\mathrm{FP}$ and RH service utilization among women at the CHS and other state and private facilities, and to explore socio-demographic determinants of RH service utilization at the CHS level. It is intended to inform policy and program reviews that will strengthen the CHS primary $\mathrm{RH}$ network in the changing health system of Vietnam.

The state health system in Vietnam consists of 4 levels: the national level with the Ministry of Health and central hospitals; the provincial level with the Provincial Department of Health and provincial hospitals; the district level with district health centers and district hospitals; and the communal level with CHSs. RH and FP services are available at all-level state health facilities: central, provincial, district hospitals and CHSs.

Despite the changes in the health sector, the CHS retains its responsibilities as the primary access point to primary RH and FP services subsidized by the state budget, and is required to meet government numerical targets on basic RH and FP service use indicators. Every CHS is staffed by at least one midwife who acts as the focal point for RH services, including antenatal and post-natal care, delivery, gynecological examination and treatment, and FP services such as IUD, oral contraceptives, and condoms. Some CHSs located close to a hospital are restricted from providing delivery services. Local residents are entitled to free services at their local CHS but not at the CHS in other communes.

In addition to everyday $\mathrm{RH}$ services, $\mathrm{CHSs}$ are entrusted with responsibilities to register and manage all pregnant women in the commune, conducting 1-day monthly antenatal check-ups. There are also 3-day semiannual RH campaigns based at the CHS with assistance of midwifes or doctors from the district hospital. The primary purpose of these campaigns is early detection and treatment of reproductive tract infections (RTIs) including sexually transmitted infections, based on clinical examination [3]. Since the restructuring of the national population program, there is a network of population collaborators affiliated with the local CHS, who have basic training in $\mathrm{RH}$ health education and services. Population collaborators conduct regular outreach communication activities, providing $\mathrm{RH}$ counseling and contraceptives (e.g. condoms, pills), and referring couples to the CHS for further FP and RH services such as IUD insertion, gynecological and antenatal check-ups [4].

Private healthcare services in Vietnam comprise three differing service structures [5,6]. Private hospital care is principally located in major cities. Compared to state hospitals, they have a reputation for their access to more advanced diagnostic and therapeutic technology, and their capacity to provide technically demanding services. Private outpatient clinics are operated by individuals or groups of full- or part-time physicians in urban, sub-urban and rural areas, under a license from provincial health authorities. They largely provide general or specialized health services for middle income patients. Third, "mobile" private practitioners-who can be nurses, assistant doctors, or retired doctors-are commonly present in rural areas, providing health services from their own homes without a license. These health practitioners are not included as part of the formal health system, although they play an important role in providing basic health services [6]. For RH services at the commune level, private providers include doctors or practitioners (e.g. midwives, assistant doctors), and traditional birth attendants, who provide home-based delivery services $[7,8]$. In addition, local pharmacies can offer the commercial sale of birth control commodities such as oral contraceptives, without prescription.

With the reduction in government subsidies for CHS facilities, equipment, and human resources development, the quality of health services at CHSs has been perceived as deteriorating and is associated with less-qualified health staff, outdated equipment, limited drugs and supplies [2]. At the same time, the private sector has been increasingly popular and is associated with convenient opening hours, more competent staff, better equipment, and effective drug prescriptions [9]. Reports suggest that increasingly, patients are seeking care at private clinics or bypassing their local CHS for higher level health facilities, willing to pay higher fees based on their perceptions of better quality and enhanced technology $[1,2,10,11]$.

\section{The Study Sites}

This study is part of the baseline assessment of a project supported by Marie Stopes International Vietnam, that aims to create public-private partnerships to improve access to services and the quality of primary RH care, in two provinces, Thua Thien Hue and Vinh Long, in Vietnam. Thua Thien Hue is located in the center of Viet Nam with a total population of $1,143,500$, of which 284,149 women are at reproductive age $(15-49)$. The province has 1 central hospital, 9 district hospitals, and 152 CHSs located in urban, semi-urban, rural, and mountainous areas. Based in the Mekong delta region, Vinh Long province has a population of $1,057,000$. The state health care network consists of $107 \mathrm{CHSs}, 8$ district hospitals, and 1 provincial hospital. People in districts bordering with Can Tho city may seek RH services at the Can Tho central hospital. Almost all CHSs in the 2 provinces are staffed by a doctor [4].

Studies sites included 1 urban district (Hue city), 2 rural districts of Thua Thien Hue, and 3 rural districts of Vinh Long. As these districts received no external support for primary RH care, they can be considered to represent the baseline for state provided RH services. In 
each of these districts, the state primary healthcare network was well-established, with each commune having a $\mathrm{CHS}$ and a team of population collaborators. In contrast, $\mathrm{RH}$ private clinics were mostly concentrated in urban areas, and were often run by a gynecologist working in a major hospital. Only 3 out of 5 rural districts had a gynecologist working in the district hospital and 2 rural districts in Vinh Long had an accredited private RH clinic (i.e. with a license from provincial health authorities) operated by this specialist [12].

\section{Methods}

The study was a cross-sectional survey, using a multistage cluster sampling design to recruit participants. The first stage selected 5 communes from each of the selected districts, using proportional to population size techniques, totaling 30 communes in the 2 provinces. The second stage involved the random selection of 1 village or residential group in each commune where 30 households were randomly drawn for interviews of all women at reproductive age (15-49). In total, 900 households with 1417 women were included in this study.

Data was collected using questionnaire-based interviews, consisting of mutiple-choice questions on respondents' socio-demographic characteristics (e.g. age, marital status, occupation, education, number of living children, income), their RH and FP service use (see Additional File 1). Women were also asked about the health facility where they attended antenatal care during their last pregnancy or received their most recent gynecological examination, and the place where they had their latest delivery. These three RH services were considered to constitute basic RH healthcare provided at the local CHS or other state health facilities in Vietnam. Women were interviewed at home by a trained interviewer who was a member of the commune Women's Union. Data collection was completed from April to May, 2010. As mentioned earlier, the research was undertaken as a baseline survey, commissioned by Marie Stopes International Vietnam for planning an intervention in the 2 selected provinces. Ethical approval was given by the Ethic Committee of the Thua Thien Hue and Vinh Long Provincial Departments of Health.

Data were entered into Epi Info, then transferred to STATA version 9.0 for processing and analyses. Ten percent of questionnaires were double entered to check consistency. Data analyses consisted of two sequential steps. First, descriptive analysis was performed of the socio-demographic characteristics of all study participants and the frequency distributions of variables of interest, including the current use of FP method(s), history of ANC, delivery, and gynecological check-up service use, and the health facility where women attended for their most recent service.
Second, logistic regression analyses were performed of factors related to the use of the following services in the local CHS: (i) antenatal check ups during the last pregnancy, (ii) their latest delivery, and (iii) their most recent gynecological examination. The dependent variable was based on whether or not women who visited a health facility for these services reported selecting their local CHS. Independent variables of interests included: women's age (above vs. below the median), number of living children (having 2 children or less vs. 3 children or more), religion (Buddhist, Catholic, other, and none), ethnicity (majority vs. minority), occupation (farming vs. other), education (secondary school or less vs. high school or more), income (4 quartile groups), current living location (urban vs. rural), and study province (Vinh Long vs. Thua Thien Hue). The statistical model for the use of $\mathrm{CHS}$ delivery services excluded those who required a cesarean section and those who reported that delivery service was unavailable at their local CHS at the time the women gave birth. Each socio-demographic variable was analyzed first as a univariate predictor to obtain a crude odds ratio (OR) and 95\% confidence intervals (CI). Significantly related variables $(p<0.05)$ were subsequently included in a multivariate analysis to obtain an adjusted OR and 95\% CI. Only factors that were significantly associated with the outcome variable in the multi-variate analytical model were retained in the final reduced model.

\section{Results}

The sample consisted of 678 women (48\%) in Vinh Long and 739 women (52\%) in Thua Thien Hue. Median age was 31 . Sixty-six percent of respondents were married; $31 \%$ were single, and $3 \%$ were widowed or divorced. The demographic characteristics of respondents are presented in Table 1.

\section{FP service use}

Among 439 single women, only 13 (3\%) reported having a current sexual partner, and 9 reported current use of a birth control method. Given these small numbers, analyses of FP service use were limited to ever-married participants $(\mathrm{n}=978)$. The rate of FP service use among ever-married women was $88.5 \%$ after excluding those who reported not using a birth control due to one of the following reasons: being pregnant, having just given birth, or being menopausal. IUD appears to be the most common method, utilized by $49 \%$ of women, followed by condoms $(16 \%)$, oral contraceptives $(15 \%)$, and the rhythm method (14\%). Male or female sterilization was used by $5.5 \%$, and injected contraceptives by $3.8 \%$ of married women. The sum of these percentages was $104 \%$ as a few women reported concurrent use of condoms and the rhythm method. 
Table 1 Socio-demographic characteristics of surveyed respondents $(n=1417)$

\begin{tabular}{|c|c|c|c|c|c|}
\hline Variable & $\mathbf{n}$ & $\%$ & Variable & $\mathbf{n}$ & $\%$ \\
\hline \multicolumn{6}{|l|}{ Province } \\
\hline Vinh Long & 678 & 48 & Religion & & \\
\hline Thua Thien Hue & 739 & 52 & Buddhist & 556 & 39 \\
\hline Age & & & Catholic & 75 & 5 \\
\hline$<=31$ & 740 & 52 & Other & 58 & 4 \\
\hline$>31$ & 677 & 48 & None & 728 & 52 \\
\hline Marital status & & & Occupation & & \\
\hline Single & 439 & 31 & Farmer & 570 & 40 \\
\hline Ever-married & 978 & 69 & Non-farming job & 847 & 60 \\
\hline Number of children & & & Location of living & & \\
\hline None & 435 & 33 & Urban & 213 & 15 \\
\hline 1 or 2 & 635 & 45 & Rural & 1204 & 85 \\
\hline$>2$ & 307 & 32 & Income & & \\
\hline Education & & & 1st quartile & 356 & 25 \\
\hline Secondary school or less & 960 & 68 & 2nd quartile & 416 & 29 \\
\hline \multirow[t]{2}{*}{ High school or more } & 457 & 32 & 3rd quartile & 296 & 21 \\
\hline & & & 4th quartile & 349 & 25 \\
\hline
\end{tabular}

Regarding the source of FP services, $71 \%$ of the 464 women using IUDs reported visiting the local CHS, with $19 \%$ selecting district hospitals, $8 \%$ private clinics, and $2 \%$ other facilities for their last IUD insertion. For condoms and other contraceptives (e.g. oral, injections), the CHS appears to be the major source, reported by $61 \%$ women, followed by population collaborators (37\%), and then pharmacies (18\%). Only $5 \%$ of women had obtained these birth control supplies from a hospital, with $2 \%$ using a private clinic (Table 2). The total percentage of $123 \%$ reflects the availability of contraceptives from multiple sources.

\section{Antenatal care service use}

Of 964 women who had ever experienced a pregnancy, 857 (89\%) reported having facility-based antenatal care with $62 \%$ having at least 3 check-ups during their last pregnancy. Among these 857 women, more than half (55\%) used the CHS, 35\% private clinics, and $31 \%$ the district hospital. Approximately $10 \%$ of women went to the provincial or central hospital for this service. The total percentage was greater than $100 \%$, as women may visit multiple health facilities during the gestational period (Table 3).

Analyses of data by provinces found that in Thua Thien Hue, the local CHS was the most favorable service provider in rural districts, attracting $76 \%$ of women, compared to district hospitals (34\%), and private clinics (15\%). In the city, private clinics ranked first, visited by $50 \%$ of women, with the local CHS and district hospital each reporting access by $32 \%$ of women. In both settings, around $5 \%$ of women reported visiting Hue central hospital for ANC services during their last pregnancy (Figure 1). In Vinh Long where the survey

Table 2 Sources of FP services

\begin{tabular}{|c|c|c|c|c|}
\hline \multirow[t]{2}{*}{ Health facility } & \multicolumn{2}{|c|}{$\begin{array}{l}\text { Last IUD insertion } \\
\qquad(n=464)\end{array}$} & \multicolumn{2}{|c|}{ Condoms/other contraceptives } \\
\hline & $\mathrm{n}$ & $\%$ & $\mathbf{n}$ & $\%$ \\
\hline $\mathrm{CHS}$ & 329 & 71.0 & 345 & 60.8 \\
\hline Pop. Collaborators & NA & NA & 208 & 36.7 \\
\hline Pharmacy & NA & NA & 102 & 18.0 \\
\hline Dist. Hospital & 86 & 18.5 & 24 & 4.2 \\
\hline Provincial/central hospital hospital & 8 & 1.7 & 5 & 0.9 \\
\hline Private clinics & 37 & 8.0 & 11 & 1.9 \\
\hline Other & 4 & 0.9 & 11 & 1.9 \\
\hline
\end{tabular}

NA: Not applicable 
Table 3 The use of antenatal check-up and delivery service by health facility

\begin{tabular}{lcccccc}
\hline Health Facility & $\begin{array}{l}\text { Antenatal } \\
\text { check-up } \\
(\mathbf{n}=\mathbf{8 5 7})\end{array}$ & $\begin{array}{c}\text { Delivery } \\
(\mathbf{n}=\mathbf{9 4 2})\end{array}$ & \multicolumn{2}{c}{$\begin{array}{c}\text { Gyn. } \\
\text { examination } \\
(\mathbf{n}=\mathbf{7 5 9 )}\end{array}$} \\
\cline { 2 - 8 } & $\mathbf{n}$ & $\mathbf{\%}$ & $\mathbf{n}$ & $\mathbf{\%}$ & $\mathbf{n}$ & $\mathbf{\%}$ \\
\hline CHS & 473 & 55.2 & 181 & 19.2 & 585 & 77.1 \\
\hline Dist. hospital & 269 & 31.4 & 351 & 37.3 & 62 & 8.2 \\
\hline Prov./Cent. hospital & 84 & 9.8 & 188 & 20.0 & 24 & 3.2 \\
\hline Private clinic & 303 & 35.4 & 106 & 11.3 & 80 & 10.5 \\
\hline Home & NA & NA & 66 & 7.0 & NA & NA \\
\hline Self-delivery & NA & NA & 22 & 2.2 & NA & NA \\
\hline Other & 6 & 0.7 & 28 & 3.0 & 8 & 1.0 \\
\hline
\end{tabular}

NA: Not applicable

only included rural communes, an almost equal proportion of women (47\% and 46\%) reported using CHSs and private clinics, with $29 \%$ visiting the district hospital, and $15 \%$ going to the provincial or central hospital for ANC services (Figure 2).

\section{Delivery service use}

Of 942 women who reported a delivery, 854 (91\%) had their latest delivery in a health facility. The district hospital was selected by the highest proportion of women (37\%), followed by provincial or central hospitals $(20 \%)$, then $\mathrm{CHS}(19 \%)$, and private providers(11\%). Only $7 \%$ of women had home-based delivery with a birth attendant and 2\% practised self-delivery (Table 3).

\section{Gynecological check-up service use}

Sixty four percent of surveyed women ( $\mathrm{n}=759$ ) reported having undertaken gynecological check-ups. During the most recent check-up, the highest percentage (77\%) visited the local CHS, $11 \%$ opted for private clinics, $8 \%$ went to the district hospital. Only 3\% went to the provincial/central hospital for this service (Table 3).

\section{Socio-demographic determinants of RH service use at the local CHS}

Table 4 presents the results of the logistic regression analyses. The analyses found that the CHS antenatal check-up and gynecological examination services were both strongly related to number of children $(<=2$ vs. $>$ 2), religion (Buddhist vs. each of other groups: Catholic, non-Buddhist and non-Catholic, and non- religious affiliation), occupation (farmers vs. other groups: government cadres, factory workers, small traders, and students), and self-reported income (first quartile vs. each of other 3 quartiles). Women with more than 2 children, having a non- Buddhist/non-religious affiliation, or living in Thua Thien Hue (compared to Vinh Long) were more likely than others to attend antenatal check-ups during their latest pregnancy, or to have their most recent gynecological examination at their local CHS.

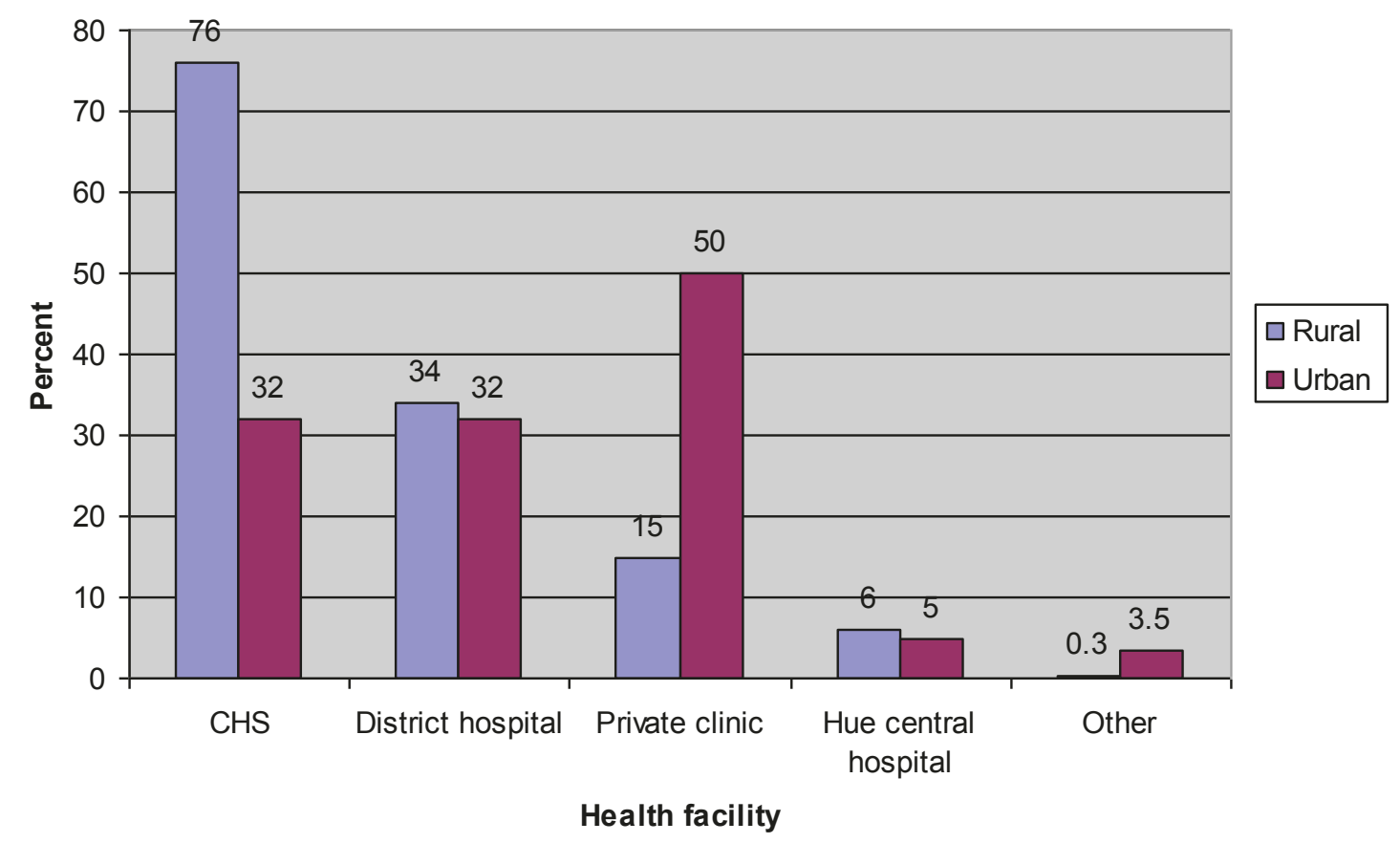

Figure 1 Health facility visited for antenatal check-ups at the latest pregnancy in Thua Thien Hue $(n=402)$. 


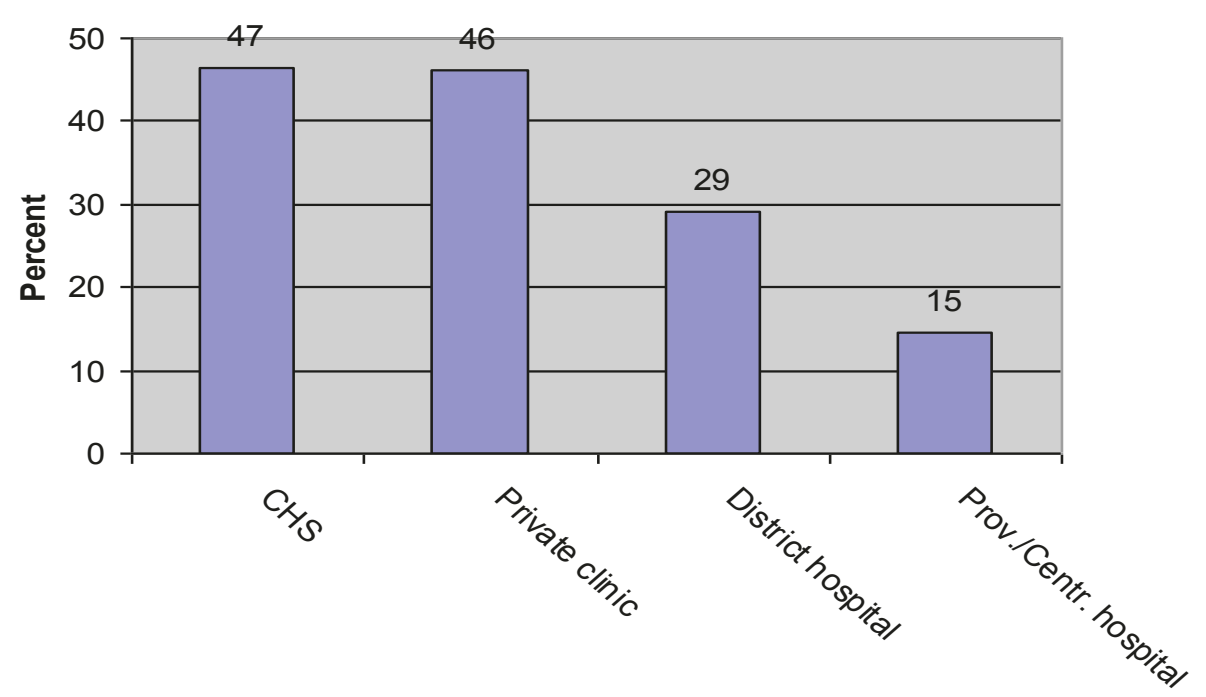

Health facility

Figure 2 Health facility visited for antenatal check-ups at the latest pregnancy in Vinh Long $(n=455)$.

Women with a non-farming occupation or earning a higher income were less likely than others to visit their local CHS for these two services. Regarding delivery service use, mothers of minority ethnic groups were more likely than those of the majority ethnic group to have their latest delivery at the local CHS, which was also true for non-Buddhist/non-religious mothers compared with Buddhist mothers. Women from non-farming occupations, or earning a higher income, were less likely to choose CHS-based delivery. It is noted that the use of CHS antenatal check-up service was significantly related to living location, with rural women more likely

Table 4 Factors related to the use of RH services available at the local CHS (Reduced logistic regression model)

\begin{tabular}{|c|c|c|c|c|}
\hline \multirow[t]{2}{*}{ Factors } & \multirow[t]{2}{*}{ Category } & \multicolumn{3}{|c|}{ OR $(95 \% \mathrm{Cl})$} \\
\hline & & Antenatal check-up $(n=835)$ & $\begin{array}{c}\text { Delivery } \\
(\mathrm{n}=577)\end{array}$ & Gynecological check-up $(n=718)$ \\
\hline \multirow[t]{2}{*}{ Children } & $<=2$ & Ref & Ref & Ref \\
\hline & $>2$ & $1.61(1.13-2.31)$ & NS & $1.62(1.01-2.06)$ \\
\hline \multirow[t]{4}{*}{ Religion } & Buddhist & Ref & Ref & Ref \\
\hline & Catholic & $2.91(1.36-6.25)$ & $3.05(1.49-6.26)$ & $3.19(1.04-9.85)$ \\
\hline & Other & $3.10(1.39-6.90)$ & $2.85(1.16-7.01)$ & $7.91(2.24-27.97)$ \\
\hline & None & $2.01(1.38-2.92)$ & $2.17(1.39-3.38)$ & $3.60(2.36-5.49)$ \\
\hline \multirow[t]{2}{*}{ Ethnicity } & Majority & Ref & Ref & Ref \\
\hline & Minority & NS & $2.20(1.32-3.69)$ & NS \\
\hline \multirow[t]{2}{*}{ Occupation } & Farming & Ref & Ref & Ref \\
\hline & Non-farming & $0.64(0.45-0.90)$ & $0.22(0.15-033)$ & $0.72(0.57-0.91)$ \\
\hline \multirow[t]{2}{*}{ Living location } & Urban & Ref & Ref & Ref \\
\hline & Rural & $2.79(1.59-4.91)$ & ND & NS \\
\hline \multirow[t]{2}{*}{ Province } & Vinh Long & Ref & Ref & Ref \\
\hline & Thua Thien Hue & $2.83(1.88-4.26)$ & NS & $3.33(2.11-5.26)$ \\
\hline \multirow[t]{4}{*}{ Income } & 1st quartile & Ref & Ref & Ref \\
\hline & 2nd quartile & $0.79(0.53-1.17)$ & $0.73(0.47-1.13)$ & $0.41(0.24-0.71)$ \\
\hline & 3rd quartile & $0.52(0.33-0.83)$ & $0.57(0.34-0.97)$ & $0.40(0.22-0.75)$ \\
\hline & 4th quartile & $0.42(0.26-0.67)$ & $0.33(0.18-0.61)$ & $0.34(0.18-0.63)$ \\
\hline
\end{tabular}


than their urban counterparts to use this CHS service. None of women in the city reported having their latest delivery at the CHS.

\section{Discussion}

This study is among the first examining the pattern of $\mathrm{RH}$ and FP service utilization at the CHS and in other health facilities in the context of change in the healthcare system in Vietnam. With basic RH services available from a range of health facilities, women in Vietnam, especially those in urbanized areas, have been given a range of alternatives. However, state services continue to dominate, though private services are playing a significant role. In general, the local CHS appears to be the most frequently used health facility for FP, $\mathrm{ANC}$, and gynecological examination services, all free or heavily subsidized. Hospitals dominate the provision of delivery services. There were marked differentials in women's selection of service providers for ANC and delivery services between rural and urban areas.

Data on behavioral RH care indicators in the selected districts were impressive with a very high proportion of married women currently using a birth control method, high rates of pregnant women having sufficient ANC and giving birth at a health facility. These data were comparable with the national-level statistics over the past 5 years [13] that reported high national rates of contraceptive use (80\%-90\%), at least 3 antenatal visits in pregnant women (87\%), and deliveries attended by trained health personnel (95\% or higher) $[14,15]$. The pattern of birth control methods currently used was also keeping with the national data that reported IUD to be the most popular method applied by around $56 \%$ of married couples [14].

The high levels of contraceptive use, with the local CHS as the major supplier, indicates that the model of providing FP services in Vietnam is effective, and able to meet local needs. Historically, the CHS has been serving as the primary access point for FP services under the national population and family planning program since early 1960s. Over time, the CHS has gained a reputation for its provision of subsidized FP services, with delivery of FP services strengthened by the population collaborator network, providing women with easy access to low-cost, community-based services. The contribution of the local pharmacy is also significant, diversifying the provision of condoms or other contraceptive commodities at the commune level. The hospital and private providers appear to have a little role in the provision of IUD services and other FP commodities (i.e. condoms or pills).

The CHS also appears to be a major provider for antenatal check-ups, particularly in the rural area, although the number of private antenatal service users was significant. This finding counters previous studies that reported lower use of primary healthcare and outpatient treatment services at CHSs compared to private clinics or hospitals $[1,16]$. Antenatal care check-ups at the CHS are subsidized and accompanied by free prenatal tetanus vaccination, and the CHS is proactive in inviting mothers to register for the monthly antenatal clinic when their pregnancy is confirmed. However, while CHSs continue to dominate the provision of ANC services, a preference for delivery in hospitals was clear in these districts, a finding consistent with rising economic status and increasing patient expectations of the health system in Vietnam $[2,8,17]$.

Living location affects the selection of ANC service providers, with rural women more likely than their urban counterparts to use the CHS. The same differential was not seen in the choice of services relating to delivery, with women living in rural areas as likely to choose a hospital as those in the city. In both settings, district hospitals have become the most popular provider for this service, while the role of the local CHS has tended to diminish. Our data support earlier studies that found a low use of CHS delivery services, with most women preferring district hospital-based delivery because of the perceived better quality of services for both mothers and newborn $[7,8]$. The data also support the qualitative study in these provinces that noted the 2-child population control policy has made couples more cautious about outcomes for their baby, choosing hospital-based delivery where they are more confident in provider's expertise and equipment, and life saving emergency care is readily available [4].

The high use of gynecological check-up services at the local CHS was attributed in part to the national $\mathrm{RH}$ semi-annual campaign. Although this national campaign is aimed at early detection and treatment of RTIs, population-based studies conducted within the last 10 years, including one study in Thua Thien Hue, reported a prevalence of RTIs ranging from $21 \%$ to $39 \%$ among women of reproductive age [18-20]. The RTIs prevalence was found to be even higher in hospital- or clinicbased studies, though these were subject to selection bias $[21,22]$. While RTIs can change overtime and vary by provinces, such high prevalence raises questions around the strategic use of CHS-based free gynecological check-ups during the national semi-annual $\mathrm{RH}$ campaign, with questions over the quality and efficacy of this service as an intervention strategy.

Private physicians were important providers for ANC services in both rural and urban areas, despite their uneven geographical distribution. With $\mathrm{RH}$ private clinics mostly concentrated in urban areas, using private services not only incurred higher fees, but also travel expenses for rural women. Yet, a significant proportion 
of rural women used private clinics during their latest pregnancy. Previous studies report criticism of state facilities and a preference for reproductive healthcare provided at private clinics, though, paradoxically, these private clinics are serviced by physicians who routinely work in state health facilities [23]. In the private clinics, clients may be entitled to direct access to more senior clinicians, and find staff more responsive, compared to their reception in state services [23]. While CHSs maintained dominance in provision of ANC services, there was a clear upwards trend for the use of private antenatal services, consistent with trends for other health service use in Vietnam [1,2].

In essence, the patterns of RH service provider choice were driven by socio-economic and geographic factors. Women of lower socio-economic status, who were farmers, earning a lower income, having more than 2 children, and living in a rural area were more likely to use antenatal, delivery, and/or gynecological check-up services at the local CHS. This finding is consistent with previous studies that found the poor tend to use the CHS more frequently than the rich $[1,24]$.

Among the 2 provinces, a higher percentage of women in Thua Thien Hue reported visiting their local CHS for ANC and gynecological check up services. This difference can be explained by the higher number of CHSs in sampled communes in Thua Thien Hue staffed by a doctor (13), compared to those in Vinh Long (10) [25]. In Vinh Long, 2 of 3 districts included in the survey had an accredited private $\mathrm{RH}$ clinic, while there were none in rural districts of Thua Thien Hue. This was reflected in the findings that more rural women in Vinh Long used antenatal check-ups at private clinics and fewer of them used this service at the CHS compared to their counterparts in Thua Thien Hue, though in both provinces, there were low levels of delivery in private facilities. This difference also indicates a shift from CHSs to private doctors for ANC services where they are locally accessible, reducing the use for services delivered through the CHS system.

The study findings should be considered in conjunction with the limitations of the research. The sample was drawn from districts purposively selected for the intervention project, and thus not representative for the whole province. Although the percentage of women who have a current sexual partner (3\%) was consistent with national data on prevalence of premarital sex among young women (5.2\%), [26] the sample of unmarried women was too small for meaningful statistical analyses. Data were self-reported, and may incur recall bias with regards to the history of $\mathrm{RH}$ service use, particularly with ANC and delivery services.

\section{Conclusions}

Although the CHS in this study retains significant utilization rates and constitutes an important provider of primary $\mathrm{RH}$ services, it is under challenge on three fronts. The first challenge is from the significant use of private practice for ANC, where clients have direct access to higher grades of health care providers, and are willing to pay higher fees for their perceptions of better quality of care. Secondly, although the semi-annual gynecological screening continues to attract significant numbers of women with its subsidized service, its effectiveness as a population strategy is questionable, and the quality of services needs evaluation. Thirdly, the preference for delivery in district hospitals over CHS is marked, and arguably, government services would do well to move towards strengthened referral services and shared care with the CHS, rather than invest in duplication of these functions at both levels.

To address these challenges, the CHS system needs to be responsive to specific local needs. In areas with accessible alternative health services reducing the need for CHS services, rationalizing of services is needed. Those CHSs that attempt to function in the shadow of hospital facilities need to be protected by referral practices and clear differentiation of services to avoid unnecessary provision of routine $\mathrm{RH}$ care by more costly staff, in higher cost level facilities. At the same time, efforts should be made to improve service quality at the local CHS as the economy improves and clients demonstrate growing demand for higher quality services. With the reduction in government subsidies, a responsive payment scheme must be developed at the CHS level that generates income for the sustainable provision of quality services, but retains subsidized services for the poor who continue to rely on their local CHS for basic reproductive healthcare.

\section{Additional material}

Additional file 1: Study questionnaire.

\section{Abbreviations}

ANC: Antenatal care; CHS: Commune Health Station; Cl: Confidence Interval; FP: Family Planning; IUD: Intra uterine device; $\mathrm{RH}$ : Reproductive Health; OR: Odd Ratios

\section{Acknowledgements}

This study is part of a project funded by European Commission, entitled: "Building capacity in local authority and private sector sexual and reproductive healthcare providers in Vietnam", and implemented through Marie Stopes International (MSIV) Vietnam. The authors would like to thank MSIV project staff for their valuable comments on the research protocol and data collection tools and their institutional support in implementing data collection. The analysis was undertaken as part of the Evidence for Health Policy in Vietnam (VINE) Project funded by the Atlantic Philanthropies. 


\section{Author details}

'Social Epidemiology and Evaluation Research Group, School of Health Sciences, University of South Australia, City East Campus, Adelaide, SA 5000 Australia. (Formerly, Vietnam Evidence for Health Policy Project, School of Population Health, University of Queensland. Health Strategy and Policy Institute, 138 Giang Vo Str., Hanoi, Vietnam. ${ }^{2}$ Vietnam Evidence for Health Policy Project, School of Population Health, University of Queensland, Herston Road, Herston 4006, Australia.

\section{Authors' contributions}

AN conceived research ideas, developed research protocol and data collection tools, and conducted data collection and data entry. AN performed data analysis and drafted the manuscript with input from $\mathrm{PH}$. PH made a substantial contribution in revising the manuscript for intellectual content. All authors reviewed and approved the final version.

\section{Competing interests}

The authors declare that they have no competing interests.

Received: 16 September 2010 Accepted: 27 September 2011 Published: 27 September 2011

\section{References}

1. Khe D, Xuan L, Eriksson B, Hojer B, Diwan VK: Primary health concept revisited: Where do people seek health care in a rural area of Vietnam. Health Policy 2002, 61:95-109.

2. Ministry of Health, WHO: Policy options for the renovation and improvement of the health system towards equity, efficiency and development. Hanoi; 2007.

3. Ministry of Health: The National Strategy for Reproductive Health for the 2001-2010 Period. Hanoi; 2002

4. Ngo DA, Hill P: Quality of reproductive health services at commune health stations in Viet Nam: implications for national reproductive health care strategy. Reproductive Health Matters 2011, 19(37):52-61.

5. Tuan T, Dung VT, Neu I, Dibley MJ: Comparative quality of private and public health services in rural Vietnam. Health Policy and Planning 2005, 20(5):319-327.

6. Ha NT, Berman P, Larsen U: Household utilization and expenditure on private and public health services in Vietnam. Health Policy and Planning 2002, 17(1):61-70.

7. Dat VD, Binns CW, Lee AH: Utilization of delivery services at the primary health care level in rural Vietnam. Social Science \& Medicine 2004, 59:2585-2595.

8. Duong DV, Lee AH, Binns CW: Measuring preferences for delivery services in rural Vietnam. Birth 2005, 32(3):194-202.

9. Ngo A, Alden D, Dinh N, Hang N: Developing and launching a government social franchise model of reproductive health care service delivery in Vietnam. Social Marketing Quarterly 2009, 15(1):71-89.

10. Ngo AD, Pham V, Ha P: The Impact of Social Franchise on the Use of Reproductive Health and Family Planning Services at Commune Health Stations in Vietnam. BMC Health Services Research 2010, 10(1):54.

11. Ngo AD, Ha P, Pham V, Truong K: Impacts of a government social franchise model on perceptions of service quality and client satisfaction at commune health stations in Vietnam. Journal of Development Effectiveness 2009, 1:413-429.

12. Marie Stopes International Vietnam: Study on market survey, situation analysis, baseline of the local actor and non-state actor providers, training need assessment and KAB. Hanoi: Marie Stopes International Vietnam 2010.

13. General Statistics Office: Population change, labor force and family planning survey-2009. Hanoi: Statistics Publishing House; 2009.

14. Ministry of Health: Health Statistics Year Book, 2008. Hanoi; 2009

15. Ministry of Health: Joint annual health review 2008 - health financing in Vietnam. Hanoi; 2009.

16. General Statistics Office: Results of the Vietnam household living standards survey 2006. Hanoi Statistics Publishing House; 2007.

17. Nguyen Thi Bich Thuan, Lofgren C, Lindholm L, Chuc NTK: Choice of healthcare provider following reform in Vietnam. BMC Health Services Research 2008, 8:162.

18. Lan PT, Lundborg CS, Phuc HD, Sihavong A, Unemo M, Chuc NT, Khang TH, Mogren I: Reproductive tract infections including sexually transmitted infections: a population-based study of women of reproductive age in a rural district of Vietnam. Sexually transmitted infections 2008, 84(2):126-132.

19. Goto A, Nguyen QV, Pham NM, Kato K, Cao TP, Le TH, Hoang QK, Le TQ Nguyen BT, Katsube $M$, et al: Prevalence of and factors associated with reproductive tract infections among pregnant women in ten communes in Nghe An Province, Vietnam. Journal of epidemiology/Japan Epidemiological Association 2005, 15(5):163-172.

20. Phan Thi Lien, Elias C, Nguyen Thi Loi, Bui Thi Chi, Nguyen Hua Phuc, Gardner M: The Prevalence of Reproductive Tract Infections in Hue, Vietnam. Studies in Family Planning 2002, 33:217-226.

21. Nguyễn Mỹ Hương, Jorgen $K$, Đỗ Thị Thu Thủy, Vibeke R: Reproductive tract infections in women seeking abortion in Vietnam. BMC Women's Health 2009, 9, 6874-1189-1181.

22. Anh PK, Ha DT, Chien DT, Thuc PT, Luong PH, Kilmarx PH, Wongchotigul V, Kitayaporn D, Rowe PJ: Prevalence of lower genital tract infection among women attending maternal and child health and family planning clinics in Hanoi, Vietnam. Southeast Asian J Trop Med Public Health 2003, 34:367-373.

23. UNFPA: Improving the Quality of Reproductive Health Care Services in Viet Nam. The Role of National Standards and Guidelines for Reproductive Health Care Services. Page 14. Hanoi: UNFPA; 2007.

24. Nguyen P, Bich Hanh D, Lavergne MR, Mai T, Nguyen Q, Phillips JF, Hughes J, Van Thuc H: The effect of a poverty reduction policy and service quality standards on commune-level primary health care utilization in Thai Nguyen Province, Vietnam. Health policy and planning 25(4):262-271.

25. Marie Stopes International Vietnam: Study on market survey, situation analysis, baseline of the local actor and non-state actor providers, training need assessment and KAB. Hanoi; 2010.

26. Ministry of Health and General Statistics Office: Survey Assessment of Vietnamese Youth. Hanoi; 2010.

\section{Pre-publication history}

The pre-publication history for this paper can be accessed here: http://www.biomedcentral.com/1472-6963/11/237/prepub

\section{doi:10.1186/1472-6963-11-237}

Cite this article as: $\mathrm{Ngo}$ and Hill: The use of reproductive healthcare at commune health stations in a changing health system in Vietnam. BMC Health Services Research 2011 11:237.

\section{Submit your next manuscript to BioMed Central and take full advantage of:}

- Convenient online submission

- Thorough peer review

- No space constraints or color figure charges

- Immediate publication on acceptance

- Inclusion in PubMed, CAS, Scopus and Google Scholar

- Research which is freely available for redistribution

Submit your manuscript at www.biomedcentral.com/submit
C Biomed Central 